\title{
Elementos para uma aproximação à prosa realista contemporânea de Sérgio Fantini
}

\author{
Ana Elisa Ribeiro* \\ Rafael Fernandes Carvalho**
}

\begin{abstract}
Resumo
Neste artigo, baseamo-nos na leitura da obra em prosa e paratextos do escritor mineiro Sérgio Fantini e em diversos trabalhos teóricos atuais para propor uma discussão sobre as nuanças do chamado "realismo" em sua literatura (conto e novela), suas relações com as gerações de escritores que emergiram na segunda metade do século XX e a inserção do autor no circuito literário e editorial contemporâneo brasileiro, especialmente porque ele frequenta diversas antologias de escritores representativos de uma época e de um modo de escrever. Procuramos mostrar os elementos - violentos e cotidianos - da prosa de Fantini, em relação a seus pares e parceiros, de ontem e hoje.

Palavras-chave: Literatura brasileira contemporânea. Sérgio Fantini. Realismo. Mercado editorial.
\end{abstract}

\section{Considerações iniciais}

A literatura brasileira é mais diversa do que podem mostrar suas distorções, como aponta Maria Valéria Rezende (2016), romancista ganhadora do Jabuti de 2015. ${ }^{1}$ Muito embora qualquer visada rápida dê conta de que a literatura em processo de legitimação tem origem no Sudeste do país, e, mais concentradamente, no Rio de Janeiro e em São Paulo, outras regiões produzem, há tempos, uma literatura digna de nota e registro, tal como ocorre em Minas Gerais, em Pernambuco ou

\footnotetext{
* Centro Federal de Educação Tecnológica de Minas Gerais - CEFET-MG. Professora do Departamento de Linguagem e Tecnologia, Bacharelado em Letras (Tecnologias da edição), Pesquisadora e docente do Programa de Pós-Graduação em Estudos de Linguagens (mestrado e doutorado) do CEFET-MG.

** Centro Federal de Educação Tecnológica de Minas Gerais (CEFET-MG). Mestrando na linha Edição, Linguagem e Tecnologia do Programa de Pós-graduação em Estudos de Linguagens. Bacharel em Letras pela Universidade de São Paulo (USP).

1 Em entrevista ao jornal O Globo, a autora diz: "No Brasil sempre foi assim: o sujeito que queria ser escritor tinha que se mudar para Rio de Janeiro ou para São Paulo. É claro que isso cria distorções". Ver Rezende (2016)
} 
no Rio Grande do Sul. ${ }^{2}$ Dalcastagné $(2008 ; 2012 ; 2012 a)$ apresenta tal distorção com a exatidão de quem estudou, aprofundadamente, centenas de romances contemporâneos brasileiros. Segundo ela, como perfil geral, nossos romances são escritos por homens brancos de classe média, urbanos e sudestinos, o que "coincide" com o perfil dos próprios personagens que os protagonizam ou ali aparecem. Ao menos é o que se pode dizer de uma distorção alimentada pela publicação de livros em editoras maiores, localizadas em grandes centros, e, portanto, mais visíveis, já que tais livros, em tese, são melhor distribuídos e propagandeados, também mais premiados e seus autores estão mais presentes em eventos, jornais, revistas e televisão, em escala nacional.

Muito embora os escritores mineiros sejam reconhecidos, tanto na historiografia quanto na contemporaneidade, a "diáspora" ainda ocorre, como aconteceu a gerações passadas, que migraram para outros estados, especialmente Rio de Janeiro e São Paulo, a fim de construir carreiras literárias - e profissionais - senão mais sólidas, ao menos mais visíveis. ${ }^{3}$ Talvez possamos afirmar que isso era visto como uma necessidade maior antes da internet e das redes sociais, no entanto não se pode dizer que os movimentos migratórios em direção aos centros nervosos do Brasil estejam extintos. Aos que ficam em seus locais de origem, talvez reste uma luta e uma militância menos visíveis, em termos nacionais, e também talvez se possa perceber menos se fizerem uma literatura mais diversa e menos parecida com o perfil geral encontrado por Dalcastagnè para um conjunto de obras publicadas nos últimos anos.

Trazer o belo-horizontino Sérgio Fantini à luz, neste artigo, tem não apenas uma intenção justa de reconhecimento da obra do autor, em plena atividade literária há cerca de quatro décadas, mas também o gesto político de abordar a obra em prosa de um escritor que vive toda a sua vida - pessoal e literária - na capital de Minas Gerais, publicando por editoras de pequeno porte, com as quais mantém não apenas uma relação comercial, mas uma parceria artística, como é o caso da Jovens Escribas, de Natal (RN), por onde têm saído seus mais recentes livros, resultado de um trabalho editorial e gráfico esmerado, que não deve nada ao de qualquer editora multinacional. ${ }^{4}$

2 Há de se considerar que muitos escritores e escritoras, originários de diversas regiões brasileiras, acabam indo residir em São Paulo, e que a imprensa ou as editoras de São Paulo ou do Rio fazem parecer que os escritores são todos dali; ou promovem certo apagamento da diversidade de suas origens, formações e esforços.

3 Interessante retomar essa história em, por exemplo, Werneck (2012) ou Marques (2015).

4 Interessante pensar na "paratopia" do escritor, discutida por Oliveira (2013), que se baseia em Dominique Maingueneau. O escritor vive essa paratopia na medida em que, ao mesmo tempo, quer se distanciar, mas está inserido nos mecanismos reguladores da arte ou da legitimação do artista. 
Sérgio Fantini figura nos catálogos de "grandes editoras" em antologias, tais como, para citar apenas algumas: Novos contistas mineiros, da editora Mercado Aberto (1988), Contos jovens, pela Brasiliense (s/d), Os cem menores contos brasileiros do século, pela Ateliê Editorial (2004, organizada por Marcelino Freire), 35 maneiras de chegar a lugar nenhum, Bertrand Brasil (2008, organizada pela escritora Ivana Arruda Leite), Cenas da favela - As melhores histórias da periferia brasileira, Geração/Ediouro (2007, organizada por Nelson de Oliveira), e a antologia da virada do milênio, Geração 90 - Manuscritos de computador, pela editora Boitempo (2001), também organizada pelo crítico e escritor Nelson de Oliveira. Nesta última antologia, Fantini apresenta um conto inédito (como os demais solicitados para compor o volume) e figura ao lado de prosadores como Luiz Ruffato, Marcelo Mirisola, João Anzanelo Carrascoza, Marçal Aquino e Marcelino Freire (apenas para mencionar os talvez mais amplamente conhecidos).

Segundo Nelson de Oliveira, escritor e organizador do livro Geração 90, estão ali "contistas que estrearam e se firmaram na última década do século XX", mas começaram como Geração 70, quando ele localiza "a primeira grande explosão do conto no Brasil" (OLIVEIRA, 2001, p. 7). A despeito do tom excessivamente jovial e de "iniciantes" com que o organizador trata o time de contistas ali presente, estamos falando de autores maiores de 30 anos, às vezes 40, na virada do século. Em sua maioria, trata-se de uma coletânea de autores (17, sendo uma mulher apenas... ${ }^{6}$ ) que, a despeito de sua qualidade, venderam pouco ou foram insuficientemente difundidos pelo país. São, todos eles, escritores que viveram a transição do impresso ao digital, daí o subtítulo da antologia, que Oliveira atribui à sugestão de Marcelino Freire. Têm também as características de serem a primeira geração cuja infância fora bombardeada pela TV, e talvez disso decorra parte de seu modo de escrever. Tal como aponta Nelson, grande parte dos contos causa "asco", o que vai ao encontro do que se diz aqui sobre "naturalismo" ou "realismo", no contexto da virada de século.

5 Aquelas "com maior poder de impacto simbólico e difusão", conforme diz Dalcastagnè (2012a). 6 Isso merece menção, mas não será focalizado aqui. Na verdade, o organizador explica que mais de 60 autores de conto se lançaram no final do século XX, mas que ele escolheu 17 para figurar no livro. Não deixa, no entanto, de fazer menção a muitos que considera merecerem destaque e ao fato de que a literatura escrita por mulheres, negros, etc. ainda não sobressaíra, na virada para o século XXI. São 14 os outros autores mencionados, entre eles um, em especial, tem se legitimado: Bernardo Carvalho. Novamente, apenas quatro mulheres são mencionadas entre os contistas que não foram publicados na antologia: Tércia Montenegro, premiada em 2015; Pólita Gonçalvez, Cláudia Lage e Fernanda Benevides de Carvalho. A única mulher que efetivamente publicou na Geração 90 foi Cíntia Moscovich. 
Em relação a Sérgio Fantini, estamos, portanto, diante de um autor considerado representativo de sua geração ou de um matiz da literatura do seu tempo, certamente influenciado por outros, tanto anteriores a ele quanto por seus pares, com quem mantém fortes relações artístico-afetivas. ${ }^{7}$ Oliveira (2001) o categoriza entre os contistas que abordam "os desvãos miúdos do cidadão comum" e tece um agradecimento que termina por reconhecer "os muros - altíssimos! - que separam culturalmente as regiões de nosso país" (OLIVEIRA, 2001, p. 13), isto é, encontrar um bom escritor fora de SP/RJ depende mesmo de boa vontade. A despeito da importância de Fantini, talvez sua obra seja menos focalizada do que outras, muita vez de menor fôlego, mas que se encontram melhor posicionadas em relação aos centros irradiadores de cultura hegemônicos do país. Melhor dizendo: irradiadores de certa cultura - um tanto ensimesmada. Fazemos aqui, portanto, o "investimento simbólico" arriscado ao qual se refere Dalcastagnè (2012), necessário à abordagem de um autor que ainda não desfruta da centralidade merecida.

\section{Realismos: persistências, renitências, reincidências e aproximações}

Tânia Pellegrini (2012) inicia a apresentação de um dossiê sobre realismo e literatura com a seguinte afirmação: "Não têm sido poucas as análises e interpretações que apontam o caráter visivelmente realista de grande parte da ficção brasileira contemporânea, ancorados nas mais diversas correntes teóricas". Segundo a estudiosa, o realismo tem a "persistente capacidade" de "transmutarse, travestir-se, transformar-se, com uma inquietante vitalidade" (PELLEGRINI, 2012, p. 11), isto é, não se trata apenas de "um conjunto de convenções estilísticas, mas um impulso que se inicia com o próprio ato de narrar" (PELLEGRINI, 2012, p. 12), o que desvincula a ideia de Realismo de uma corrente literária passada, historiográfica, conforme aprendemos na escola.

Para Pellegrini (2012), o realismo possui "nuances e gradações" e assume, hoje, papel de destaque em nossa literatura, o que é facilmente perceptível, por exemplo, em resenhas de revistas, jornais, em estudos acadêmicos ${ }^{8}$ ou nos

7 Não é por acaso que o autor costuma contar com vários nomes conhecidos da literatura nacional para escrever quartas capas, orelhas, apresentações e posfácios de seus livros, a exemplo dos que aqui serão citados. O livro Novella, de 2013, tem ilustração de capa de Marçal Aquino.

8 Ver, por exemplo, Oliveira (2013) sobre a obra de Bernardo Carvalho, ou Silva (2007) sobre Fernando Bonassi (dono de uma narrativa "brutal"), além de Azevedo (2007) sobre Marçal Aquino e Bonassi, que ela chama de autores de um "realismo sujo e um pouco espetacular". 
paratextos $^{9}$ das obras que ganham mais destaque. Para Pellegrini, o realismo é uma "postura geral" e um "método" (descritivo) a compor uma literatura que retorna, "ciclicamente", ao real (PELLEGRINI, 2012, p.12). Suas características atuais somam-se às mais conhecidas na historiografia, gerando uma lista que pode ser assim resumida: fragmentação, colagem, elipses e elisões e a reorganização das condições sociais atuais, como o caos urbano, a desigualdade social, a violência, a corrupção política, a sofisticação tecnológica, para citar apenas algumas. As "nuances e gradações" desse tal realismo gera adjetivos propostos aqui e ali para a caracterização da literatura contemporânea, como é o caso, por exemplo, do "realismo performático", de Karl Erik Schølhammer, ou outros mencionados por ele, ${ }^{10}$ como neo-realismo, realismo indexical, realismo psicótico, etc.

O dito "Realismo" praticado na literatura brasileira contemporânea não é resultado de um movimento gratuito, sem laços com a história literária do país. O Realismo/Naturalismo, além de ser um capítulo de vulto em nossa historiografia, modificou o que era escrito até então - séc. XIX, fazendo-se influente até os dias de hoje. A idealização difundida na literatura romântica de certa época, especialmente nos livros de José de Alencar, Joaquim Manuel de Macedo, entre outros, passou a não ser mais a motivação principal dos autores daquele período. Essa mudança de paradigma foi ocasionada por um processo histórico. Tais mudanças não se dão de maneira gratuita, repentina, mas decorrem dos processos lentamente gestados durante os anos do século XIX. Segundo Alfredo Bosi (1994), com negritos nossos:

O Realismo ficcional aprofunda a narração de costumes contemporâneos da primeira metade do século XIX (Stendhal, Balzac, Dickens, Hugo) e de todo o século XVIII (Lesage, Diderot, Defoe, Fielding, Jane Austen...). Nas obras desses grandes criadores do romance moderno já se exibiam poderosos dons de observação e de análise. (...) Desnudam-se as mazelas da vida pública e os contrastes da vida íntima; e buscam-se para ambas causas naturais (raça, clima, temperamento) ou culturais (meio, educação) que lhes reduzem de muito a área de liberdade. $\mathrm{O}$ escritor realista tomará a sério as suas personagens e se sentirá no dever de descobrir-lhes a verdade, no sentido positivista de dissecar os móveis do seu comportamento. (BOSI, 1994, p. 169).

Essas características evidenciavam uma literatura nascente calcada no real, indo do vago ao típico, do idealizante ao factual, regida pelas necessidades 
objetivas do ambiente (BOSI, 1994). Ou seja, há, aí, a necessidade do contexto dirigindo-nos pela leitura. Bosi (1994, p. 167-168) nos fala a respeito de uma "atitude de aceitação da existência tal qual ela se dá aos sentidos", e lança mão de imagens conhecidas que permitem ao leitor reconhecer-se nelas. Passa a existir um elemento que influenciará a leitura desses livros. Assim, a literatura passa a ser uma espécie de espelho do leitor, mas não um reflexo apenas externo, e sim um que propicia a "reflexividade" (DALCASTAGNÉ, 1999). Como o leitor enxergase dentro do texto, pois os livros agora falam de cenários, pessoas tangíveis, situações verossímeis, esses elementos levam a uma reflexão sobre si.

Segundo Fernandes (2010), há de se considerar também o Modernismo para se chegar aos dias de hoje ou à era pós-moderna, conforme perspectiva assumida pela autora. A citação extensa nos parece ser merecida:

Pelo projeto realista do Século XIX, formulado principalmente por escritores franceses e russos, o romance deveria seguir determinadas convenções para simular um real que, acreditava-se, copiava uma concreta realidade exterior. Com o modernismo, o texto desvinculase desse projeto mimético. Os escritores passam a acreditar que devem criar uma outra realidade, autônoma, espécie de duplo da vida humana, de uma perspectiva social ou psicológica, por meio do artesanato da linguagem e da experimentação formal. (...) Já na perspectiva pós-moderna, um dos principais papéis do romance é suscitar reflexões acerca das fronteiras entre os "mundos" criados pela arte e os mundos criados por outras formas de linguagem. O deslocamento das fronteiras entre a realidade narrada e a realidade exterior não repousa apenas na crença de uma interação entre elas, mas decorre, sobretudo, do questionamento da própria natureza do que se chama de mundo real, vista também como uma espécie de ficção, construída sempre a partir de interesses de grupos dominantes, por meio de códigos que regulam toda a produção de significados, organizando a comunicação, a produção de saber e o comportamento dos indivíduos na sociedade. (FERNANDES, 2010, p. 48).

Nesse sentido, há uma espécie de "volta" ao Realismo acusada por leitores especializados quando se deparam com contos e romances de uma geração que desponta entre os anos 1970 e 1990, no Brasil. Ainda que a etiqueta do Realismo ou a do Naturalismo pareçam retornar por conta das características encontradas nos livros de escritores contemporâneos, estamos, é claro, diante de nuanças da narrativa que não poderíamos encontrar um século ou mais atrás. 
Conforme veremos a seguir, a "realidade" e a identificação entre "homem comum" e leitor são elementos notáveis na narrativa de Fantini. A reflexividade defendida por Dalcastagnè (1999) surge aqui nas palavras de vários colaboradores que compõem o paratexto dos livros do autor, todos eles também escritores, seus pares, seus leitores.

\section{Sérgio Fantini, vida e obra}

Sérgio [Francisco Cruz] Fantini nasceu em maio de 1961, na cidade de Belo Horizonte, onde reside. Começou suas publicações em 1976 - isto é, aos 15 anos com fanzines e livretos de poesia, que vendia em bares da capital mineira, como fez uma geração inteira de poetas brasileiros. Nosso foco, neste trabalho, no entanto, é sua obra em prosa, iniciada no final dos anos 1980, quando da primeira publicação de sua novela "Diz xis", conforme historia a apresentação do escritor Francisco de Morais Mendes no Silas (2011). A mesma novela foi republicada por Fantini, com alterações, em dois livros posteriores: Materiaes (2000) e Silas (2011).

É importante mencionar sua biobibliografia, que conta já, em 2016, com quatro livros de prosa, além da reedição de A ponto de explodir e de um quinto livro publicado no corrente ano. ${ }^{11}$ Materiaes, sua estreia como contista por uma editora, veio à luz pelas mãos do escritor Sebastião Nunes, então editor da DuBolso, de Sabará (MG). Na época, iniciava-se uma coleção intitulada Moritvri te Salvtant, sendo Fantini seu segundo volume (o primeiro era André Sant'Anna, com o livro Amor).

Materiaes foi publicado em 2000, em formato quase quadrado (18x20cm), papel pólen, 120 páginas, nas quais foram distribuídas três novelas ("Diz xis", "Suíte bar" e "Rugas"), gênero literário ao qual Fantini tem se dedicado, a despeito de não ser muito popular no Brasil, como diz o autor, na apresentação de Novella (2013). Em seguida, Coleta seletiva foi lançado, pela editora Ciência do Acidente, de São Paulo, pelo editor e escritor Joca Reiners Terron. Trata-se, no entanto, de uma seleta de poemas a que não nos dedicaremos aqui.

11 Lambe-lambe foi lançado em 2016, após a escrita deste artigo, pela editora potiguar Jovens Escribas, com ilustrações do quadrinista mineiro Guga Schultze. Diversas cidades brasileiras receberam seu lançamento, começando por João Pessoa (PB), em junho. São 50 textos que retratam personagens urbanos como mendigos, prostitutas e policiais, sob o olhar de um fotógrafo lambe-lambe. O posfácio é de Luiz Ruffato, autor consagrado da literatura brasileira, e a quarta capa, da poeta mineira Adriane Garcia. 
O próximo volume em prosa foi A ponto de explodir, em edição do autor, em 2008, reeditado pela editora Jovens Escribas, de Natal (RN) em 2014. Antes dessa reedição, Fantini lançou Silas e Novella pela Jovens Escribas, respectivamente em 2011 e 2013, obtendo, em 2014, com este último, indicação para a semifinal do Prêmio Portugal Telecom (atual Oceanos). São, portanto, 40 anos de carreira como escritor, sendo os últimos 25 dedicados à prosa, especialmente ao conto e à novela, em editoras de pequeno porte, angariando o respeito dos pares e dos leitores.

Sérgio Fantini é considerado sucessor de uma geração reconhecida em Minas como Geração Suplemento ${ }^{12}$ ou mesmo dos poetas marginais dos anos 1970. É o que diz sobre ele o escritor Jaime Prado Gouvêa, na orelha do livro A ponto de explodir, publicado, em primeira edição, em 2008:

Sérgio Fantini faz parte de uma geração que sucedeu à minha, a do Suplemento Literário do Minas Gerais, num tempo em que já não mais havia o alicerce do porto seguro que Murilo Rubião representou para nós, mas que floresceu aqui e ali, quase ao acaso, gerando nomes como Jeter Neves, Francisco de Morais Mendes e Carlos Herculano Lopes - para ficarmos apenas na prosa -, que continuam segurando a tradição do conto mineiro. (GOUVÊA, 2008).

Semelhantemente, é o que apontam o poeta Sebastião Nunes, na quarta capa do livro Silas (2011), e Francisco de Morais Mendes, no posfácio do mesmo livro, respectivamente:

Sérgio Fantini é fruto tardio do bando de galhofeiros que, na década de 1970, atacou com sua controvertida papelada a bastilha da poesia brasileira, dividida na época em dois batalhões furiosos: de um lado, vanguarda radical; do outro, conservadorismo irredutível. Não havia meio termo, até que a marginália decidiu jogar tudo pro alto e atacar com seus poemas de fôlego curto e humor grosso, impressos em gráfica de subúrbio. Vindo depois do vendaval experimental, SF (...) manteve a princípio o gosto pela edição tosca em sua ótima literatura, até Materiaes, quando pulou de vez a cerca. Daí em diante não foi mais um jovem-promissor-herdeiro da geração mimeógrafo. Já era irmão de sangue dos que subiram o morro da melhor literatura da geração, muito além do precário e do rústico. (NUNES, 2011)

12 Tratava-se de escritores atuantes desde o início dos anos 1960, mas especialmente após a criação do jornal Suplemento Literário de Minas Gerais, por Murilo Rubião e outros, em circulação até os dias de hoje. Entre esses poetas, contistas e romancistas estão, além de Rubião, Affonso Ávila, Laís Corrêa de Araújo (a única mulher entre eles, destaque-se), Wander Piroli, Jaime Prado Gouvêa (atual superintendente do Suplemento Literário), entre outros. Sobre isso, ver, por exemplo: Maroca (2013). 
Fantini dialoga, explicitamente, com esta geração surgida nos anos 1970, e também com os de sua geração, como Luiz Roberto Guedes, Marçal Aquino, Marcelo Carneiro da Cunha, Luís Giffoni, Antônio Barreto, Jeter Neves e tantos outros. (MENDES, 2011)

\section{Sérgio Fantini em paratextos por seus pares}

Em relação às características de sua prosa, especialmente das novelas, coincidem as impressões de pares como Marçal Aquino (SP), Francisco de Morais Mendes (MG), Ernani Ssó (RS), Sebastião Nunes (MG), Luiz Vilela (MG) e Sérgio Sant'Anna (MG), apenas para citar alguns.

$\mathrm{Na}$ orelha do livro Materiaes, apropriadamente intitulada "Um legista da realidade", o escritor e roteirista Marçal Aquino afirma que "Sérgio Fantini é um daqueles sujeitos que misturam a vida com a literatura. De forma radical." É essa "mistura" que desenha uma relação com o que já se chamou de "realismo" ou "naturalismo" em literatura, em termos historiográficos. Continua Aquino, ao caracterizar a prosa de Fantini: “(...) SF, sabiamente, só tem um assunto: a vida. E ao preferir os vícios às virtudes, sua prosa está o tempo inteiro nos lembrando de que a humanidade não é nem um pouco de confiança.” E daí decorre uma comparação, outras vezes reiterada, do texto de Fantini com o jornalismo-verdade, e mais realista até do que a própria reportagem:

Isso é jornalismo, poderia dizer um desses "agrimensores literários" de plantão. Aí é que está: a fidelidade de Fantini às buscas e inquietações da linguagem permite que ele chame a vida de você. $\mathrm{O}$ jornalismo do nosso tempo costuma tratá-la de senhora e usar luvas na hora de lidar com ela. (AQUINO, 2000).

No mesmo diapasão, Jaime Prado Gouvêa (2008) assim descreve o texto de Sérgio Fantini, na orelha de A ponto de explodir, reinvestindo na ideia do repórter:

Em seus contos o cotidiano miúdo é vigiado de perto e tem suas nuances e pequenas tragédias registradas pelo narrador, com a precisão de um repórter que vai tecendo as linhas da vida e dos sentimentos aprisionados pulsando em silêncio, com a contenção de uma bomba talvez ativada, talvez não. (GOUVÊA, 2008). 
Enquanto isso, Francisco de Morais Mendes termina de emoldurar esta literatura tão próxima quanto possível da vida comum (com negritos nossos) e mesmo da reportagem, muito embora seja preciso lembrar que o objetivo desses paratextos é capturar, seduzir e aproximar o leitor:

Os textos reunidos neste volume, mais que flagrantes da vida do personagem Silas, revelam as opções ou, numa dicção mais dramática, as obsessões do escritor Sérgio Fantini. Sem a pretensão de hierarquizá-las, a primeira é a escrita; a segunda, um modo de olhar; a terceira, o que esse olhar recorta da realidade. (MENDES, 2011, p. 121).

(...) o olhar desvia-se dos grandes embates para se deter nas miudezas do cotidiano. Deixa passar o de gravata e repara no sem gravata. Deixa passar os que correm pingando suor e saúde, para mirar no caído a um canto. (MENDES, 2011, p. 122-123.)

(...) trabalho paciente e persistente do escritor em busca desse homem comum, qualquer um, cada um. (MENDES, 2011, p. 124.)

Quanto à sua linguagem, que é, afinal, a matéria básica do literário, os autores dos paratextos dos livros de Fantini são unânimes, auxiliando-nos a compor um perfil de sua obra com muitos adjetivos do campo "naturalista" (com negritos nossos):

Este Materiaes contém ainda um conjunto de contos que exercita uma prosa precisa, exata, que prefere chamar as coisas por seus nomes. (...) A literatura de Sérgio Fantini provoca desconforto. É crua, contundente, amarga. (AQUINO, 2000).

Sérgio Fantini é um matador frio, do tipo que a literatura anda precisando para sobreviver. (...) Textos ágeis, cortantes e vigorosos, sem perder a ternura (...) A ponto de explodir é um painel de contos escritos com a fúria de quem sabe cortar a realidade com a destreza da palavra, impiedosa e limpa como uma faca, mas sem camuflar o lirismo e a beleza de um texto que trata a pele da alma como uma flor em carne viva. (GOUVÊA, 2008).

O texto dele é seco, coloquial, não dá mole para a literatura. As histórias - drama sem drama, traçados com pudor, com ironia parecem a maleta do espião: as armas e os segredos vêm sob fundo falso. (SSÓ, 2008, quarta capa). 
É uma escrita enxuta. Sem enfeites. Retira sua força da oralidade obviamente lapidada. (MENDES, 2011, p. 121).

E essa dita maneira de descrever, mostrar, reportar a "realidade", ao menos na forma de literatura, é ainda apontada como a responsável pelo efeito sobre o leitor. Segundo Marçal Aquino (2000), no livro Materiaes:

(...) Os leitores sempre terminam os textos com a sensação, muitas vezes incômoda, de ter vivenciado esta ou aquela experiência, de já ter cruzado com determinado personagem pelas ruas ou de ter presenciado certos diálogos. (...) Não há nada mais detestável do que escritores que enxergam no eufemismo um comparsa para sua falta de coragem literária.

Estamos diante de uma escrita comprometida com a vida - não falei que Fantini era autor de um só assunto? Assunto que, por sinal, anda ausente de boa parte dos livros que são lidos hoje em dia, no Brasil e fora dele. Talvez por isso estejamos vivendo tão bovinamente conformados. (AQUINO, 2000).

Isto é, Fantini faz uma literatura necessária, contundente, formadora, ao contrário de uma outra, que, em falta, não ajudaria em nosso projeto civilizador. Para Aquino, se essa literatura corajosa está em falta, explica-se nosso modo "bovinamente" conformado de viver.

Finalmente, trazemos aqui o excerto de Ronaldo Correia de Brito na orelha do livro Silas (2011):

Teu livro é muito bom. A rainha do Egito é uma obra-prima, um conto perfeito. Sinto dores de estômago quando leio o que escreves. Há um retrato de viver que me incomoda pelo sem sentido, apesar da afirmativa que é isso mesmo. Abre-se uma cerveja, várias, preparase uma macarronada aos domingos e só. Existe esse mundo sem nenhuma transcendência, sem nenhuma mitologia? Ou você inventou tudo isso? (BRITO, 2011).

$\mathrm{O}$ "mundo sem nenhuma transcendência" ao qual se refere Brito é uma opção do escritor por construir personagens majoritariamente que narram em primeira pessoa e talvez nos façam entrar no jogo literário e acreditar em suas vidas miúdas e vis. Com a linguagem, Fantini faz isso tão bem que nos convence, talvez, de que aquelas sejam mesmo vidas possíveis, reais, até palpáveis, bastando ir à esquina ou sentar-se no bar (ambiente comum em suas histórias) para encontrar seus personagens. 
Talvez a especialidade de Sérgio Fantini possa ser tratada pelo que Azevedo (2007) chama de "performatividade", isto é, "jogo entre servir-se das repetições naturalizadas ao mesmo tempo em que se é capaz de ocultar sua artificialidade". (AZEVEDO, 2007, p. 86). A voz que narra veste-se de seus preconceitos, de uma linguagem fortemente coloquial e de uma pulsação capazes de "performar" ao ponto de confundir. Ou convencer por certo tempo. É preciso, para isso, ter o que Marçal Aquino chama de "coragem literária", no paratexto de Materiaes (FANTINI, 2000), já que, como lembra Azevedo (2007), há riscos envolvidos na apropriação de obras assim, entre os quais ser compreendida como a reiteração de preconceitos e estereótipos. Vejamos, por exemplo, um trecho de Novella:

Saia jeans roxa com bainha desfiada; tamanquinhos; camisa social, branca, abotoada até o pescoço, as pontas amarradas em nó - meu deus, Maria!, quem, senão mulheres que querem dar, amarra a camisa acima do umbigo? Cabelos escondidos sob lenço. (FANTINI, 2013, p. 88).

O preconceito contra a mulher está aqui "performado" na voz de um narrador que precisa ser compreendido como um personagem do conto "Muito silêncio por nada", no livro Novella. Uma discussão ferrenha sobre a violência contra a mulher poderia julgar o texto literário em suas fricções com a realidade. Além desse, há outros trechos, nas novelas e nos contos de Fantini, que poderiam ser problematizados em relação ao negro ou aos homossexuais que circulam pelas ruas e bares de seus narradores, sob preconceito e sob a pulsação da vida. Mas este é apenas um efeito que pode buscar tanto a discussão e a denúncia, quanto, para alguns, a afirmação.

Azevedo nos lembra de certa crítica que acusa "a rarefação da linguagem" e uma "postura transgressiva vazia, limitada a um enxame de palavrões e imagens grosseiras no texto" (AZEVEDO, 2007, p. 89), o que poderia ser visto, por essa mesma crítica, em certos contos de Fantini. Dalcastagnè (2008) aponta, por exemplo, o perigo de que a literatura repercuta e ecoe discursos de preconceito e ódio sob o manto mitológico do "texto literário". No entanto, é preciso considerar a "performatividade", em relação à construção proposta pelo escritor, inclusive em seu projeto de produzir um "efeito de real". ${ }^{13} \mathrm{O}$ narrador, que narra em primeira pessoa, quase não dá nomes aos personagens, descreve com detalhes um ambiente

13 "Efeito de realidade", conforme aprendemos em Roland Barthes. 
comum, quase visível ao leitor, quase íntimo, em uma linguagem popular, muito próxima da que se ouve nas esquinas, incluindo-se a expressão do preconceito e do ódio, e é, ainda assim, literatura. No caso de Sérgio Fantini, sem abandonar uma enunciação lírica e mesmo poética (não nos esqueçamos de que seu início na vida literária foi como poeta).

Estão lá também o machismo persistente, a violência - narrada à beira da sordidez, entre outros elementos que dão a estes textos aquela nuança que tem sido considerada certo tipo de realismo contemporâneo. Vejamos mais trechos:

Então pega a mochilinha do Gabriel lá no carro, Gervásio.

Ah, meu bem, deixa eu acabar essa cerveja.

Ele nunca faz as coisas na primeira vez que Inácia pede. Precisa mostrar que quem manda é ele. Um ranço machista antigo, do tempo em que eles estiveram separados. Ela aceitou voltar; ele abaixou a crista, mas ainda tem dessas coisas porque sabe que nós sabemos que ele não apita nada. (FANTINI, 2008, p. 74).

Logo depois que saiu do estabelecimento, ouviram-se tiros. Quando Elizabeth correu para ver o que tinha acontecido, encontrou Valderato no chão: balas na barriga e, fatais, na cabeça. O corpo rodopiou e escorreu feito gosma. $\mathrm{O}$ sangue se espalhou na calçada, pedaços de cérebro grudaram na porta, Uma perna ficou dobrada. $\mathrm{O}$ que restou da cabeça tombou sobre o ombro esquerdo. (FANTINI, 2008, p. 46).

Estão presentes aqui elementos que Pellegrini elenca como a "descrição minuciosa de atrocidades, sevícias e escatologia” (PELLEGRINI, 2008, p. 15). Recorrendo bastante a isso, Fantini dá também voz a personagens que estão longe da intelectualidade bem-vestida ou de uma vida burguesa. $\mathrm{O}$ trabalho assalariado, pesado, a prostituição, a boemia e ainda o adultério ou as moradias precárias são seus temas e espaços preferenciais. Trata-se, certamente, de uma literatura urbana, ${ }^{14}$ em que a violência é parte de muitos episódios. Nas palavras de Pellegrini (2008), o "baixo mundo" protagoniza as narrativas, em suas torpezas, valendo citar alguns outros adjetivos que qualificaram uma literatura surgida depois dos anos 60 do século XX, no Brasil: feroz e brutalista. ${ }^{15}$ No entanto, muito embora

14 Pode ser de interesse estudar o texto de Süssekind (2003), em que a autora menciona "catalogações" de lugares e tipos humanos urbanos, o que em muito lembra a prosa de Sérgio Fantini. O ensejo permite reiterar que o autor lançou mais um volume em 2016. Neste, um fotógrafo lambe-lambe protagoniza a experiência de observar e conviver com os tipos que frequentam um parque, na região central de uma grande cidade.

15 São, respectivamente, Antônio Cândido e Alfredo Bosi que assim a qualificam. Ambos são 
possa despertar o asco apontado por Nelson de Oliveira, os contos e novelas de Sérgio Fantini são capazes de enxertar lirismo na violência, especialmente porque o "como" ele faz literatura impressiona tanto quanto "o que" escolhe para narrar.

\title{
5 Considerações finais
}

Nem só de alguns estados sudestinos vive a literatura contemporânea brasileira. O conto e a novela de Sérgio Fantini, nascido e residente da capital de Minas Gerais, publicado há vários anos, por editora potiguar, participam, com força $\mathrm{e}$ vivacidade, da produção literária contemporânea, cujos matizes realistas são tocados por ele com lirismo e firmeza.

Neste trabalho, procuramos mostrar a forte relação entre os livros em prosa de Sérgio Fantini e o escopo do que vem sendo tratado como a nova literatura herdeira do realismo. Para isso, traçamos uma composição dos discursos sobre a obra desse autor, menos conhecido do que outros, mas tão importante quanto todos para a literatura brasileira viva. Tais discursos podem ser compilados dos paratextos de seus livros e inferidos de sua participação - e legitimação - em antologias importantes, conforme o caminho metodológico que nos propusemos. É, no entanto, também possível recolher sobre Fantini os discursos da imprensa, sua participação em eventos e sua militância literária, que ajudariam a colorir um quadro deste grande escritor brasileiro vivo, cuja obra está disponível.

\section{Elements for an approach to contemporary realistic literature of the brazilian writer Sérgio} Fantini

\begin{abstract}
Sérgio Fantini is a contemporary Brazilian writer from Belo Horizonte, Minas Gerais. In this paper, we discuss his books and the elements of his writing style, based in new theories of "realism" and in paratexts of
\end{abstract}


his books. We also discuss Sérgio Fantini as a participant of a literary Brazilian context, within a contemporary frame composed by other writers, in the editorial and artistic circuit. Sérgio Fantini and his texts are part of important and relevant anthologies and legitimating events. We show here how realistic and contemporary this writer is, because of his violent and daily literature.

Keywords: Brazilian contemporary literature. Sérgio Fantini. Realism. Publishing.

\section{Referências}

AQUINO, Marçal. Um legista da realidade (Orelha). In: FANTINI, Sérgio. Materiaes. Sabará, MG: DuBolso, 2000.

AZEVEDO, Luciene. Representação e performance na literatura contemporânea. Aletria, v.16, p. 80-93, jul./dez. 2007.

BESSIÈRE, Jean. Notas sobre o estado da literatura e da crítica francesas contemporâneas - a respeito de duas vias da criação literária hoje. Tradução de Adriana Santos Corrêa. Cerrados, Brasília, v. 22, n. 36, p. 29-46, 2013.

BOSI, Alfredo. História concisa da literatura brasileira. 32 ed. São Paulo: Cultrix, 1994.

BRITO, Ronaldo Correia de. Orelha. In: FANTINI, Sérgio. Silas. Natal, RN: Jovens Escribas, 2011.

DALCASTAGNÈ, Regina. Para não ser trapo no mundo: as mulheres negras e a cidade na literatura brasileira contemporânea. Estudos de Literatura Brasileira Contemporânea, Brasília, UnB, v. 44, p. 289-302, 2014.

DALCASTAGNÈ, Regina. Um território contestado: literatura brasileira contemporânea e as novas vozes sociais. Iberic@l: Revue d'études ibériques et ibéro-américaines, Paris, v. 2, p. 11-15, 2012.

DALCASTAGNÈ, Regina. Um mapa de ausências. In: DALCASTAGNÈ, Regina. Literatura brasileira contemporânea: um território contestado. Vinhedo: Horizonte/Rio de Janeiro, UERJ, 2012a. p. 147-196.

DALCASTAGNÈ, Regina. Entre silêncios e estereótipos: relações raciais na literatura brasileira contemporânea. Estudos de Literatura Brasileira Contemporânea, Brasília, v. 31, p. 87-110, 2008.

DALCASTAGNÈ, Regina. Espaço de cumplicidade: a representação da figura 
materna na literatura brasileira contemporânea. Cerrados (UnB), Brasília, n.9, p. 147-154, 1999.

FANTINI, Sérgio. Materiaes. Sabará, MG: DuBolso, 2000.

FANTINI, Sérgio. A ponto de explodir. Belo Horizonte: Uainote, 2008.

FANTINI, Sérgio. Silas. Natal, RN: Jovens Escribas, 2011.

FANTINI, Sérgio. Novella. Natal, RN: Jovens Escribas, 2013.

FERNANDES, Maria Lúcia Outeiro. Perspectivas pós-modernas na literatura contemporânea. Olho d'água, São José do Rio Preto, v.2, n.2, p.42-55, 2010.

GENETTE, Gérar. Paratextos editoriais. Tradução de Álvaro Faleiros. Cotia, SP: Ateliê Editorial, 2009. (Coleção Artes do Livro).

GOUVÊA, Jaime Prado. Orelha. In: FANTINI, Sérgio. A ponto de explodir. Belo Horizonte: Uainote, 2008.

MAROCA, Viviane Monteiro. Experimentalismo e liberdade no Suplemento Literário do Minas Gerais. (1966-1975). Em tese. Belo Horizonte, v. 19, n. 3, p.77-93, set./dez., 2013.

MARQUES, Fabrício. Uma cidade se inventa. Belo Horizonte: Scriptum, 2015.

MENDES, Francisco de Morais. Um homem comum. Posfácio. In: FANTINI, Sérgio. Silas. Natal, RN: Jovens Escribas, 2011.

NUNES, Sebastião. Quarta capa. In: FANTINI, Sérgio. Silas. Natal, RN: Jovens Escribas, 2011.

OLIVEIRA, Nelson de. (Org.) Geração 90. Manuscritos de computador. São Paulo: Boitempo, 2001.

OLIVEIRA, Paulo César S. de. O romance contemporâneo brasileiro: ficção, teoria, história. Revista de Letras, v. 1, p. 1-19, 2013.

PELLEGRINI, Tânia. No fio da navalha: literatura e violência no Brasil de hoje. In: Regina Dalcastagnè. (Org.). Ver e imaginar o outro - Alteridade, desigualdade e violência na literatura brasileira contemporânea. Vinhedo: Horizonte, 2008, p. 41-56.

PELLEGRINI, Tânia. Apresentação. Realismo: modos de usar. Estudos de Literatura Brasileira Contemporânea, Brasília, n.39, p.11-17, jan./jun.,2012. REZENDE, Maria Valéria. Maria Valéria Rezende lança romance inspirado em 
sua atuação contra ditadura. Entrevista a Guilherme Freitas. O Globo, Cultura, 6 jan. 2016. Disponível em: <http://oglobo.globo.com/cultura/livros/maria-valeriarezende-lanca-romance-inspirado-em-sua-atuacao-contra-ditadura-3-18407009>. Acesso em: 9 fev. 2016.

SCHØLLHAMMER, Karl Erik. Realismo afetivo: evocar realismo além da representação. Estudos de Literatura Brasileira Contemporânea, Brasília, n. 39, p. 129-148, jan./jun., 2012.

SILVA, Maurício. Histórias de rua ou sexo \& violência. O realismo suburbano de Fernando Bonassi. Aletria, v.15, p.98-104, jan.jun., 2007.

SSÓ, Ernani. Quarta capa. In: FANTINI, Sérgio. A ponto de explodir. Belo Horizonte: Uainote, 2008.

SÜSSEKIND, Flora. Desterritorialização e forma literária. Literatura brasileira contemporânea e experiência urbana. In: MUÑOZ, Boris; SPITTA, Silvia (Org.) Más Allá de la Ciudad Letrada: Crónicas y Espacios Urbanos. Pittsburgh: Biblioteca de America/Universidad de Piitsburgh, 2003, p. 353-378.

WERNECK, Humberto. O desatino da rapaziada. Jornalistas e escritores em Minas Gerais (1920-1970). São Paulo: Companhia das Letras, 2012.

Recebido em 15/02/2016.

Aceito em 13/09/2016. 